\title{
Liquid-phase synthesis of butyl levulinate with simultaneous water removal catalyzed by acid ion exchange resins
}

\author{
Montserrat Iborra, Javier Tejero, Carles Fité, Eliana Ramírez, Fidel Cunill ${ }^{*}$ \\ Department of Chemical Engineering and Analytical Chemistry, Faculty of Chemistry, \\ University of Barcelona, C/ Martí I Franquès, 1, 08028 Barcelona, Spain \\ *e-mail address: $\underline{\text { fcunill@ub.edu }}$
}

\begin{abstract}
The liquid-phase synthesis of butyl levulinate by esterification of levulinic with an excess of 1-butanol (initial molar ratio 1:3) and simultaneous water removal has been studied at atmospheric pressure and at the boiling point of the reacting medium. The catalytic performance of ten commercial sulfonic resins has been compared: four gel-type and six macroreticular. For both type of resins the levulinic acid conversion was complete after 4$6 \mathrm{~h}$ and no byproducts derived from the acid were detected. Selectivity of 1-butanol towards the ester was about 95\%, di-butyl ether and butenes being the detected 1-butanol-derived byproducts. Among the tested catalysts, gel-type resins with low crosslinking degree showed the highest activity, what could be attributed to a higher accessibility to active centers in polar medium. In additional experiments where initial reactants content was at stoichiometric relation, the levulinic acid conversion was lower (82-85\%), while selectivity of 1-butanol towards the ester was slightly higher, because of the lower 1-butanol concentration.
\end{abstract}




\section{Introduction}

Since lignocellulosic biomass is the most abundant and bio-renewable carbon source on earth, it is considered as one of the most attractive candidates to contribute to the biofuel pool, helping to replace fossil fuel. Levulinic acid (LA) is a valuable chemical that can be produced from biomass at an affordable price, as low as $1 \$ / \mathrm{kg}$. It is a useful platform chemical that has been highlighted as a promising chemical building block by the United States Department of Energy in 2004 [1] and 2010 [2]. Alkyl levulinates stand out among LA-derived compounds because of their favorable properties as a biofuel: inexpensive feedstock, low volatility, poor water solubility, and high oxygen content $[3,4]$. They can be used as an oxygenate additive to gasoline [5] and diesel fuel depending on their boiling point. Compared to fatty acid esters, alkyl levulinates have a higher potential as blend components in diesel formulations, because of better oxidative stability, low-temperature properties, and a lower tendency to gum formation [6,7]. The addition ratio of alkyl levulinates to fuel falls in the range $0.5-20 \%$ vol. [8]; Junbluth [9] showed a blending octane number of 107 for isobutyl levulinate and sec-butyl levulinate (10\%vol). Ethyl levulinate is the most studied ester until now but other ethers with higher molar mass such as butyl levulinate have appeared as potential biofuel components.

Butyl levulinate (BL) can be produced by esterification of LA with 1-butanol (Fig. 1). Nowadays, biobutanol has become a more economical product thanks to the application of acetone-butanol-ethanol fermentation technology (ABE process) to lignocellulose. However, the literature on the synthesis of BL via esterification of LA with 1-butanol has been sparse until the last decade (Table 1). The use of commercial solid acid catalysis and the development of new and effective ones for the synthesis of BL is now an active ongoing research area. The esterification of LA with 1-butanol is a reversible reaction limited by a 
low equilibrium constant $\left(\mathrm{K}_{\mathrm{a}}=0.64\right.$ at $\left.50^{\circ} \mathrm{C}\right)$ [10]. LA conversion is favored operating at stoichiometric excess of alcohol to shift the equilibrium towards products, the molar ratio of alcohol to LA ranging from 3 to 10 . However, a large dilution ratio leads to mass transfer limitations of the reactant and favors intermolecular alcohol dehydration [8].

\section{Figure 1}

The esterification of LA with butanol has been studied over several types of solid catalysts (Table 1) [11-23] and it has been also obtained via enzymatic catalysis [24]. Yang et al. [23] showed that the synthesis of BL catalyzed by sulfonated solids and by liquid acids of different acid strength is sensitive to strength. They also showed the positive effect of $-\mathrm{SO}_{3} \mathrm{H}$ density $\left(\mathrm{mmol} \cdot \mathrm{g}^{-1}\right)$ and the easy accessibility to these groups. Alternatively, BL has also been obtained by reaction of furfuryl alcohol $[25,27]$ and of $\alpha$-angelica lactone [27] and butanol, although both syntheses promote polymer formation.

The homogeneous esterification cannot be discarded because of the acid nature of the levulinic acid. However, its reaction rate is low below $100{ }^{\circ} \mathrm{C}$ [28]. Interestingly, the proposed mechanism shows the previous formation of the pseudo-butyl levulinate as

\section{Figure 2}

an intermediate product that suffers a trans-esterification to normal-butyl levulinate., enhanced at a higher temperature and acid strength $[27,28]$.

Due to the availability of cellulose as raw material, some work has been made in BL production directly from cellulose using heterogeneous acid catalysts. Using temperatures 
between $160-200{ }^{\circ} \mathrm{C}$ and a high excess of butanol, low to moderate BL yields (15-60\%) are obtained $[29,30]$. The main drawback is the formation of byproducts and polymers (humins) that lead to a reduction of the selectivity to butyl levulinate and to catalyst deactivation [3133].

To the best of our knowledge, attempts to produce $\mathrm{BL}$ from $\mathrm{C}_{6}$ sugars are scarcely reported in the open literature. From fructose, a yield of $62.8 \%$ was obtained catalyzed by $\mathrm{Fe}_{2}\left(\mathrm{SO}_{4}\right)_{3}$ [27]. Using CNT-PSSA (poly(p-styrene sulfonic acid)-grafted carbon nanotubes) and the ion exchange resin Amberlyst 15 as catalysts BL yields of 87 and $89 \%$ was obtained, respectively, at $120^{\circ} \mathrm{C}$ and $24 \mathrm{~h}$ [34]. Over metal sulfates at $190{ }^{\circ} \mathrm{C}$ and after $2 \mathrm{~h}$, a BL yield of $62.8 \%$ by butanolisis of fructose [21].

Although yields reported by various studies are difficult to compare because of very different reaction systems, general trends emerge from data in Table 1, i.e., high conversions and selectivities using high molar ratio of 1-butanol to LA $\left(R_{B u O H / L A}\right.$, in the range 5 to 10$)$, as well as the moderate working temperatures. As already above mentioned, the main drawbacks were the formation of fructose-derived polymers and deactivation for most of the catalysts. 
Table 1. Synthesis of butyl levulinate by direct esterification of levulinic acid and from the reaction of sugars and 1-butanol

\begin{tabular}{|c|c|c|c|c|c|c|c|c|c|c|}
\hline $\begin{array}{l}\text { Alcohol/ } \\
\text { Solvent }\end{array}$ & $\begin{array}{c}\text { Acid/ } \\
\text { Substrate }\end{array}$ & $\begin{array}{c}\text { Molar ratio } \\
\text { 1-butanol/LA } \\
\text { o sugar } \\
\end{array}$ & Catalyst & $\begin{array}{c}T \\
\left({ }^{\circ} \mathrm{C}\right)\end{array}$ & $\begin{array}{c}t \\
(\mathrm{~min})\end{array}$ & $\begin{array}{c}\text { LA Conv } \\
(\%)\end{array}$ & $\begin{array}{l}\text { Sel. } \\
(\%)\end{array}$ & $\begin{array}{c}\text { Alkyl } \\
\text { ester yield } \\
(\%) \\
\end{array}$ & Catalyst reuse / Humins & Ref \\
\hline 1-Butanol & LA & $6 / 1$ & $\mathrm{HPA} / \mathrm{K} 10$ & 120 & 240 & 97 & 100 & 97 & 3 times & {$[13]$} \\
\hline 1-Butanol & Fructose & $160 / 1$ & CNT-PSSA & 120 & 1440 & $>99$ & 87 & 87 & Humins & {$[34]$} \\
\hline 1-Butanol & Fructose & $160 / 1$ & Amberlyst-15 & 120 & 1440 & $>99$ & 89 & 89 & $\mathrm{~N} / \mathrm{A}$ & {$[34]$} \\
\hline 1-Butanol & LA & $7 / 1$ & H-BEA & 120 & 240 & 82 & 100 & 82 & 5 runs & {$[11]$} \\
\hline 1-Butanol & LA & $6 / 1$ & Zr-MOF & 120 & 300 & 99 & 100 & 99 & No deactivation after 3 cycles & {$[19]$} \\
\hline 1-Butanol & LA & $6 / 1$ & Micro/meso-HZ-5 & 120 & 240 & N/A & $\mathrm{N} / \mathrm{A}$ & 98 & 6 cycles & {$[12]$} \\
\hline 1-Butanol & LA & $2 / 1$ & $\mathrm{WO}_{\mathrm{x}} / \mathrm{ZrO}_{2}$ & 120 & 120 & 67 & 98 & 66 & N/A & [28] \\
\hline 1-Butanol & LA & $7.8 / 1$ & $\begin{array}{c}\text { Sulfated } \\
\mathrm{ZrO}_{2} / \mathrm{KIL}-2\end{array}$ & 100 & 420 & 80 & $\mathrm{~N} / \mathrm{A}$ & N/A & N/A & {$[18]$} \\
\hline 1-Butanol & cellulose & 40/1 wt. & Sulfated zirconia & 200 & 60 & $\mathrm{~N} / \mathrm{A}$ & $\mathrm{N} / \mathrm{A}$ & 13 & Strong deactivation & {$[29]$} \\
\hline 1-Butanol & LA & $3 / 1$ & Dowex $50 \mathrm{Wx} 2$ & 80 & 480 & 94 & 99.9 & 94 & No humins & {$[15]$} \\
\hline $\begin{array}{c}\text { 1-Butanol } \\
/ \mathrm{H}_{2} \mathrm{O}\end{array}$ & Fructose & $80 / 1$ & Dowex $50 \mathrm{Wx} 2$ & 120 & 480 & 99.9 & 39.1 & 39 & Humins & {$[16]$} \\
\hline 1-Butanol & LA & $10 / 1$ & Aquivion mP98 & 110 & 1440 & 76 & $\mathrm{~N} / \mathrm{A}$ & $\mathrm{N} / \mathrm{A}$ & $\begin{array}{c}\text { No byproducts } \\
>5 \text { cycles }\end{array}$ & {$[17]$} \\
\hline 1-Butanol & cellulose & 40/1 wt. & $\begin{array}{l}\mathrm{Fe}_{2}\left(\mathrm{SO}_{4}\right)_{3} / \\
\mathrm{Al}_{2}\left(\mathrm{SO}_{4}\right)_{3}\end{array}$ & 194 & 240 & 100 & 40.3 & 40.3 & 5 times & {$[30]$} \\
\hline 1-Butanol & LA & $10 / 1$ & Aquivion mP98 & 110 & continous & $>99$ & $\mathrm{~N} / \mathrm{A}$ & $\mathrm{N} / \mathrm{A}$ & $\mathrm{N} / \mathrm{A}$ & {$[17]$} \\
\hline
\end{tabular}




\begin{tabular}{|c|c|c|c|c|c|c|c|c|c|c|}
\hline 1-Butanol & LA & $5 / 1$ & HPA/C-Sil-1 & 100 & 300 & 93 & 99 & 92 & No deactivation after 4 cycles & {$[14]$} \\
\hline 1-Butanol & Fructose & $100 / 1$ & $\mathrm{Fe}_{2}\left(\mathrm{SO}_{4}\right)_{3}$ & 190 & 180 & & & 62.8 & Humins & {$[21]$} \\
\hline 1-Butanol & LA & $5 / 1$ & Al-MCM41 & 120 & 480 & N/A & $\mathrm{N} / \mathrm{A}$ & 90 & Several runs & {$[20]$} \\
\hline 1-Butanol & LA & $5 / 1$ & Sulfonated carbon & 100 & 240 & 90.5 & 100 & 90.5 & No deactivation after 5 cycles & {$[23]$} \\
\hline 1-Butanol & LA & $5 / 1$ & TNTs- $\mathrm{SO}_{3} \mathrm{H}$ & 120 & 240 & 86.8 & 99.7 & 86.5 & High stability after 7 cycles & {$[22]$} \\
\hline
\end{tabular}


LA esterification is an equilibrium reaction that produces water and can be catalyzed by acidic ion exchange resins. A high LA conversion (practically equilibrium conversion) can be obtained by operating with a stoichiometric excess of butanol and removing the formed water. In addition, water removal minimizes the inhibitory effect of water on the catalytic activity of resin.

The aim of present work is to find the experimental conditions and suitable ion exchange resin in a batch reactor, equipped with a Dean-Stark device for water removal, to maximize butyl levulinate production by reaction of 1-butanol with levulinic acid. Specifically, the main goal is to study the catalytic activity of acidic ion exchange resins on direct esterification of levulinic acid with simultaneous water removal. This study also allows inferring the effect of the structure and morphology of the tested resins on their catalytic activity.

\section{Experimental section}

\subsection{Chemicals}

Levulinic acid (98\% and $2 \%$ water) and 1-butanol ( $>99.5 \%$, max. $0.05 \%$ water) content were used as in its commercial form (Across Organics). Butyl levulinate (98\%, 2\% levulinic acid) and dibutyl ether (DBE) with $99 \%$ purity and $1 \%$ of butanol content were supplied by Sigma Aldrich and Across Organics, respectively and used for calibration purposes. Table 2 shows the most relevant properties of reactants and products.

Table 2. Relevant properties of reactants and product.

\begin{tabular}{|c|c|c|c|c|}
\hline Properties & 1-Butanol & $\begin{array}{l}\text { Levulinic } \\
\text { acid }\end{array}$ & $\begin{array}{c}\text { Butyl } \\
\text { levulinate }\end{array}$ & Water \\
\hline CAS number & $71-36-3$ & $123-76-2$ & $2052-15-5$ & $732-18-5$ \\
\hline Molecular mass (g/mol) & 74.12 & 116.12 & 172.22 & 18.02 \\
\hline
\end{tabular}




\begin{tabular}{lcccc} 
Density $\left(25^{\circ} \mathrm{C}, \mathrm{kg} / \mathrm{m}^{3}\right)$ & 810 & 1147 & 974 & 998 \\
Boiling point $\left({ }^{\circ} \mathrm{C}\right.$, at $\left.760 \mathrm{mmHg}\right)$ & 118 & 245.5 & 237.8 & 100 \\
Vapor pressure at $25^{\circ} \mathrm{C}(\mathrm{Pa})$ & 885 & - & 5 & 3169 \\
Solubility in water $\left(\mathrm{g} / \mathrm{L}\right.$, at $\left.25^{\circ} \mathrm{C}\right)$ & - & 275 & 1.3 & - \\
Cetane number & 21 & - & 14 & - \\
\hline
\end{tabular}

\subsection{Catalyst}

As catalysts, gel-type and macroreticular sulfonic resins were used to check their performance for LA esterification with $\mathrm{BuOH}$ specifically: Amberlyst 15 (A15), Amberlyst 16 (A16), Amberlyst 35 (A35), Amberlyst 36 (A36), Amberlyst 39 (A39), Amberlyst 46 (A46) and Amberlyst 121 (A121), from Rohm and Haas, and Dowex 50Wx2 (D2), Dowex50Wx4 (D4) and Dowex50Wx8 (D8), from Aldrich. They were chosen to cover a wide range of macroreticular and gel-type resins properties and characteristics, shown in Table 3. Before use, resins were washed with deionized water, dried at ambient temperature and later at $110^{\circ} \mathrm{C}$, first at atmospheric pressure and then overnight under vacuum at the same temperature. Final water content was less 3\% w/w (Karl-Fisher titration). Commercial particles sizes were used in all the experiments. 
Table 3. Characteristics and structural parameters of resins in the dry state and swollen in water

\begin{tabular}{|c|c|c|c|c|c|c|c|c|c|c|}
\hline \multirow[b]{2}{*}{ Type $^{\mathrm{a}}$} & \multirow[b]{2}{*}{ Catalyst } & \multirow[b]{2}{*}{ Sulfonation $^{\mathrm{a}}$} & \multirow{2}{*}{$\begin{array}{l}T_{\max } \\
\left({ }^{\circ} \mathrm{C}\right)\end{array}$} & \multirow{2}{*}{$\begin{array}{c}{[\mathrm{H}]^{+\mathrm{b}}} \\
(\mathrm{mmol} / \mathrm{g})\end{array}$} & \multirow{2}{*}{$\begin{array}{c}\text { DVB } \\
(\%)\end{array}$} & \multicolumn{2}{|c|}{ Dry state $^{\mathrm{c}}$} & \multicolumn{2}{|c|}{ Swollen in water ${ }^{\mathrm{f}}$} & \multirow{2}{*}{$\begin{array}{c}{[\mathrm{H}]^{+} / V_{\mathrm{sp}}} \\
\left(\mathrm{mmol} / \mathrm{cm}^{3}\right)\end{array}$} \\
\hline & & & & & & $\begin{array}{c}S_{\mathrm{g}}^{\mathrm{d}} \\
\left(\mathrm{m}^{2} / \mathrm{g}\right)\end{array}$ & $\begin{array}{c}V_{\mathrm{g}}^{\mathrm{e}} \\
\left(\mathrm{cm}^{3} / \mathrm{g}\right)\end{array}$ & $\begin{array}{c}S_{\mathrm{g}} \\
\left(\mathrm{m}^{2} / \mathrm{g}\right)\end{array}$ & $\begin{array}{c}V_{\mathrm{sp}}^{\mathrm{g}} \\
\left(\mathrm{cm}^{3} / \mathrm{g}\right)\end{array}$ & \\
\hline Macroreticular & A46 & $\mathrm{SS}$ & 150 & 0.87 & 25 & 57 & 0.26 & 186 & 0.19 & 4.57 \\
\hline high & A35 & $\mathrm{OS}$ & 150 & 5.32 & 20 & 34 & 0.21 & 199 & 0.50 & 10.6 \\
\hline crosslinking & A15 & MS & 120 & 4.81 & 20 & 42 & 0.33 & 192 & 0.62 & 7.76 \\
\hline Macroreticular & A16 & MS & 120 & 4.80 & 12 & 1.7 & 0.013 & 46 & 1.14 & 4.21 \\
\hline low & A36 & $\mathrm{OS}$ & 150 & 5.40 & 12 & 21 & 0.14 & 68 & 1.26 & 4.29 \\
\hline crosslinking & A39 & MS & 130 & 4.81 & $7-8$ & 0.09 & $3 \cdot 10^{-4}$ & 56 & 1.64 & 2.93 \\
\hline \multirow{4}{*}{ Gel-type } & A121 & $\mathrm{MS}$ & 130 & 4.80 & $<2$ & - & - & - & 3.15 & 1.52 \\
\hline & D2 & MS & 150 & 4.98 & 2 & - & - & - & 2.68 & 1.80 \\
\hline & D4 & MS & 150 & 4.95 & 4 & 0.011 & - & - & 1.92 & 2.58 \\
\hline & D8 & MS & 150 & 4.83 & 8 & - & - & - & 1.40 & 3.44 \\
\hline
\end{tabular}

${ }^{a}$ Mono-sulfonated (MS), over-sulfonated (OS), and sulfonated only near the polymer surface (SS)

${ }^{\mathrm{b}}$ Acid capacity. Titration against a standard base

${ }^{c}$ By adsorption-desorption of $\mathrm{N}_{2}$ at $77 \mathrm{~K}\left(\mathrm{~N}_{2}\right.$ for $\mathrm{S}_{\mathrm{g}} \geq 1 \mathrm{~m}^{2} / \mathrm{g} ; \mathrm{Kr}$ for $\left.\mathrm{S}_{\mathrm{g}}<1 \mathrm{~m}^{2} / \mathrm{g}\right)$

${ }^{d}$ Specific surface by the BET method

e Volume of $\mathrm{N}_{2}$ adsorbed at a relative pressure $\mathrm{P} / \mathrm{P}_{0}=0.99$

${ }^{\mathrm{f}}$ ISEC method

${ }^{g}$ specific volume of swollen polymer 
Resin morphology depends significantly on the polarity of the medium, as shown the properties in the dry state and swollen in water (Table 3). Resins shrink in a non-polar medium, and they can swell largely when immersed in a polar medium, like in the presence of water. Therefore, properties in the dry state would be related to the resin behavior in nonpolar reacting media, while properties obtained in the swollen state would describe better the resin behavior in polar media. Figure 3 shows a picture of the morphology of both kinds of resins in the dry and swollen state. Three types of pores can be distinguished in resins, depending on their size: micro-, meso-, and macropores. In the dry state, gel-type resins contain only micropores, and mesoporous appear when these resins swell in a polar medium and disappear on deswelling. Macroreticular resins present a permanent porosity with all three types of pores.

Swelling effects determine the catalytic activity of resins for both gel-type and macroreticular resins. Accessibility to inner active centers of gel-type resins is extremely hindered in the dry state because the polymeric matrix is collapsed but enhanced when the resin swells. Swelling is also important for macroreticular resins, despite their permanent macropores system, because more than $95 \%$ of acid centers are located within the gel-phase [35], which can become accessible in the swollen state. Therefore, macroreticular resins present generally a higher catalytic activity in non-polar media compared to gel-type resins, due to acid centers located in its surface (5\%) and in a part of the gel zone. In the swollen state, the acid centers that are accessible are also those located in the gel-phase (Fig.3). Furthermore, both types of sulfonic resins present a great affinity for water, which is adsorbed preferentially in front of alcohols.

Figure 3 
An additional difficulty to describe the catalytic behavior of the resins is that the chain density of the gel-phase matrix, which determines the accessibility to inner active centers, is not uniform. A useful description of morphology on the swollen state can be obtained from the Inverse Steric Exclusion Chromatography technique (ISEC) [36]. In that method, macropores and mesopores are described by the model of cylindrical pores, while micropores are described in terms of the model proposed by Ogston [37], where micropores are seen as spaces between randomly oriented rigid rods representing the polymer chains. The specific volume of the swollen polymer, $V_{\mathrm{sp}}$ (volume of the free space plus that occupied by the skeleton) is the characteristic parameter of such a model. The Ogston model distinguishes polymer zones of different polymer chain concentration in terms of total rod length per volume unit of the swollen polymer, $\mathrm{nm} / \mathrm{nm}^{3}$. Table 3 shows the $V_{\text {sp }}$ values of the tested resins. As it can be seen, $V_{\text {sp }}$ decreases as DVB percentage increases for both gel-type and macroreticular resins. Low $V_{\mathrm{sp}}$ values indicate a high density of polymer mass in the swollen state and, as a result, small and stiff spaces are available, and they are poorly accessible even for small molecules. Conversely, high $V_{\text {sp }}$ values are associated with a low density of polymer mass and, thus relatively large spaces, which can be accessible for even large molecules.

\subsection{Apparatus}

Figure 4 shows the experimental set-up that consisted of a Pyrex round-bottom distilling flask (1 L), used as the reactor, connected to a Dean-Stark burette $(25 \mathrm{~mL})$, equipped with a Dimroth reflux condenser. The Dean-Stark device allowed to collect the condensed vapor, resulting in two immiscible liquid phases: the organic phase is returned into the reactor and water is collected until $25 \mathrm{~mL}$ and after drained into the receiving flask. 


\section{Figure 4}

\subsection{Analysis}

The aqueous and organic liquids were analyzed at the end of the experiment by using a split mode operation in an HP6890A GLC apparatus equipped with a TCD detector. A $50 \mathrm{~m} \times$ $0.2 \mathrm{~mm} \times 0.5 \mu \mathrm{m}$ methyl silicone capillary column was used to separate and determine reactants and products. The column was temperature programmed to start at $50{ }^{\circ} \mathrm{C}$ with a 10 ${ }^{\circ} \mathrm{C} / \mathrm{min}$ ramp until $250{ }^{\circ} \mathrm{C}$ and held for $6 \mathrm{~min}$. Helium ( $\geq 99.998 \%$, Linde) was used as the carrier gas with a total flow rate of $30 \mathrm{~mL} / \mathrm{min}$.

\subsection{Procedure}

The reactor was loaded with $400 \mathrm{~mL}$ of $\mathrm{BuOH} / \mathrm{LA}$ mixture (3.1 moles of $\mathrm{BuOH}$ and 1.02 moles of $\mathrm{LA}, \mathrm{R}_{\mathrm{BuOH} / \mathrm{LA}}=3$ ) and with about $2.8 \mathrm{~g}$ of dry catalyst. Then, the flask was put in the thermostatic bath at enough temperature to maintain the boiling point, and the magnetic stirring device was switched on at 200rpm. The reacting mixture warmed up and, after 30 40 min, the first drop was collected into the burette. That instant was taken as the starting time of the reaction, and the sampling began. Temperature and condensed water volume were monitored every circa $5 \mathrm{~min}$ until $18 \mathrm{~mL}$ of water was collected, i.e., the volume of the formed stoichiometric water. At the end of the experiment ( 3 to $6 \mathrm{~h}$ ), the remaining liquid of the reactor and the burette content were analyzed. The amount of catalyst $(0.8 \% \mathrm{w} / \mathrm{w}) \mathrm{was}$ far below to the average value, $5-10 \%$, generally accepted for avoiding saturation of the reacting medium by the catalyst. Experiments were performed at atmospheric pressure and at the boiling point of the reacting mixture, which varied accordingly to the evolution of the reaction medium composition. 


\subsection{Calculations}

The synthesis of butyl levulinate from levulinic acid and 1-butanol by direct esterification does not involve extensive side reactions. The main detected byproduct was dibutyl ether (DBE), formed by dehydration of 1-butanol. Others byproducts such as 1-butene, 2-butene, isobutene, isobutanol and 1,1,di-butoxy-butane, were detected in a very low amount: only butenes were taken into account in calculations (considered as a single compound), estimated from the mass balance. LA selectivity towards $\mathrm{BL}$ reaches $100 \%$, and therefore it has not been included in later calculations. $\mathrm{BuOH}$ conversion, the selectivity of $\mathrm{BuOH}$ towards $\mathrm{BL}$, the yield of $\mathrm{BuOH}$ to $\mathrm{BL}$ and selectivity of $\mathrm{BuOH}$ towards butenes have been calculated by Equations 1 to 4, respectively:

$$
\begin{aligned}
& X_{\mathrm{BuOH}}=\frac{\{\text { mole of reacted } \mathrm{BuOH}\}}{\{\text { initial mole of } \mathrm{BuOH}\}}=\frac{n_{\mathrm{BuOH}}^{o}-n_{\mathrm{BuOH}}}{n_{\mathrm{BuOH}}^{o}}=\frac{n_{\mathrm{BL}}+2 n_{\mathrm{DBE}}+n_{\mathrm{Butenes}}}{n_{\mathrm{BuOH}}+n_{\mathrm{BL}}+2 n_{\mathrm{DBE}}+n_{\mathrm{Butenes}}} \\
& S_{\mathrm{BuOH}}^{\mathrm{BL}}=\frac{\{\text { mole of reacted BuOH to BL }\}}{\{\text { mole of reacted BuOH }\}}=\frac{n_{\mathrm{BL}}}{n_{\mathrm{BL}}+2 n_{\mathrm{DBE}}+n_{\mathrm{Butenes}}} \\
& Y_{\mathrm{BuOH}}^{\mathrm{BL}}=X_{\mathrm{BuOH}} S_{\mathrm{BuOH}}^{\mathrm{BL}}=\frac{\{\text { mole of reacted BuOH to BL }\}}{\{\text { initial mole of BuOH }\}} \\
& S_{\mathrm{BuOH}}^{\mathrm{Butenes}}=\frac{\{\text { mole of reacted BuOH to Butenes }\}}{\{\text { mole of reacted BuOH }\}}=\frac{n_{\mathrm{Butenes}}}{n_{\mathrm{BL}}+2 n_{\mathrm{DBE}}+n_{\mathrm{Butenes}}}
\end{aligned}
$$

The reaction time has been standardized as the contact time to be able to compare evolution among different experiments, because in each run initial composition and catalyst mass, $\mathrm{W}_{\text {cat, }}$ varied slightly:

$$
\{\text { Contact time }\}=\frac{t W_{\text {cat }}}{n_{\mathrm{LA}}^{o}}
$$


In order to estimate the experimental error, three replicated runs were made by using A35 as representative of the macroreticular type and D8 for the gel-type resins. The replicated runs show a very good overlap in both temperature and collected water evolutions, and the experimental error was estimated to be less than $5 \%$. The same value was estimated to the accuracy of the yield of butenes trough Equation 4. The carbon balance was fulfilled within $3 \%$.

\section{Results and discussion}

\subsection{Description of an experiment}

The experimental runs were carried out at atmospheric pressure, the reaction mixture was continuously heated to maintain the boiling point of the reacting system, which varied accordingly to its composition $\left(110-128^{\circ} \mathrm{C}\right)$, and vapors were condensed and returned into the reactor after the removal of the formed water. As an example of the result of a typical experiment, Figure 5 shows the evolution of the reactor temperature and the amount of collected water in the Dean-Stark burette. Several stages can be distinguished. At the initial instant, i.e., when the first drop of condensed vapor appears, the temperature is about $120^{\circ} \mathrm{C}$, close to the boiling point of 1-butanol, because it is in large excess. In the beginning, temperature increases to reach a maximum, due to the BL formation, volatile byproducts (in comparison with levulinic acid and butyl levulinate) are accumulating into the liquid. First, the amount is not high enough as for affecting the boiling point but from a determinate accumulation, byproducts and /or the azeotrope water-butanol can affect it and leads to its decrease until they are withdrawn from the system. Then the increase of temperature increases again regularly until LA is totally consumed, the volume of collected water being about $18 \mathrm{~mL}$, i.e., the stoichiometric amount. It is to be noted that, beyond the instant of the minimum temperature, the water withdrawal rate is a rough measure of the $\mathrm{BL}$ formation rate.

\section{Figure 5}




\subsection{A screening study over ion-exchange resins}

A run without resin was performed at the same initial conditions. After 4 hours, LA conversion was about $51 \%$ showing clearly that the reaction took place through homogeneous catalysis due to the acid nature of LA. However, as can be seen in Table 4, with a similar real-time, LA conversion was roughly half than that obtained in the presence of resins.

Figures 6 and 7 show temperature and removed water evolutions for gel-type and macroreticular resins, respectively. Table 4 shows that LA conversion was practically $100 \%$ for all the resins, and the contact time needed for gel-type resins with low crosslinking was shorter, which means that essayed gel-type resins showed the highest activity. The final contact time can be used as the unique criterion for the resin screening since no significant differences among the assayed resins are observed in the rest of parameters $(\mathrm{BuOH}$ conversion, $\mathrm{BuOH}$ selectivities, and yields), but for $\mathrm{A} 46$. Thus, attending to the contact time, gel-type resins with low crosslinking (all but D8) would be preferred to macroreticular ones. A larger value of $V_{\mathrm{sp}}$ (see Table 3), i.e., the volume of swollen gel phase, can explain that fact, because it is related to better accessibility to acid sites. During the experiments, the ion exchange resins are swollen as long as relatively large amounts of alcohol, levulinic acid and water saturating the liquid of reactor are present and shrunk in large BL concentration. Table 5 shows in detail the particle size and the relative volume increase swelled in water and 1butanol with respect to air available for some assayed resins. It can be seen that the increase due to swelling in 1-butanol is slightly lower than in water for the majority of resins. As Table 5 also shows, swelling increases at decreasing DVB percentage. Thus, A121 and D2 present the highest swelling effect, whereas A46 shows the lowest one. As long as LA is 
present in the reacting system, water is formed. Thus, beyond the initial period, when water is uptaken by the resin and the liquid (following the corresponding partition coefficient), and until the end of the run, a small amount of water is present in the reacting medium together with 1 butanol excess. As a result, swelling promotes non-permanent pores, and accessibility is facilitated during the reaction. As for selectivity, no significant difference within the experimental error has been observed among the different types of resins at the end of the run (Table 4), even as for butenes formation. It is worth noting the agreement between the highest value of $S_{B u O H}^{D B E}$ obtained for A16 and the lowest for A46 with the results obtained for pure 1-butanol dehydration [38]. However, with A46 selectivity of butanol towards BL is the highest due to this resin is only sulfonated in the more external zone of the bead and can accommodate big molecules more easily. It is to be noticed that at the end of the experimental runs, the evolution of temperature and removed water do not present a zero slope, because 1-butanol dehydrations to DBE and to butenes continue.

Table 4. Conversions, selectivities, yields and contact time at the end of experiments for each assayed resin (atmospheric pressure, $R_{\mathrm{BuOH} / \mathrm{LA}}=3$ )

\begin{tabular}{cccccccccc}
\hline Catalyst & $\begin{array}{c}\text { Contact } \\
\text { time }\end{array}$ & $\boldsymbol{X}_{\mathbf{L A}}$ & $\boldsymbol{X}_{\text {BuOH }}$ & $\boldsymbol{S}_{\text {BuOH }}^{\text {BL }}$ & $\boldsymbol{S}_{\text {BuOH }}^{\text {DBE }}$ & $\boldsymbol{S}_{\text {BuOH }}^{\text {Butenes }}$ & $\boldsymbol{Y}_{\text {BuOH }}^{\text {BL }}$ & $\boldsymbol{Y}_{\text {BuOH }}^{\text {DEE }}$ & $\boldsymbol{Y}_{\text {BuOH }}^{\text {Butenes }}$ \\
\hline A46 & 780 & 100 & 31.0 & 95.6 & 0.97 & 3.47 & 29.6 & 0.30 & 1.08 \\
A35 & 643 & 99.8 & 34.5 & 91.2 & 5.15 & 3.64 & 31.5 & 1.77 & 1.25 \\
A15 & 618 & 99.8 & 32.3 & 93.6 & 3.16 & 3.29 & 30.2 & 1.02 & 1.06 \\
A16 & 643 & 99.8 & 33.0 & 90.1 & 5.86 & 4.01 & 29.8 & 1.94 & 1.33 \\
A36 & 554 & 99.5 & 34.6 & 91.2 & 5.18 & 3.60 & 31.6 & 1.79 & 1.25 \\
A39 & 586 & 100 & 33.7 & 93.7 & 3.42 & 2.88 & 31.6 & 1.15 & 0.97 \\
\hline A121 & 406 & 100 & 33.7 & 94.9 & 2.26 & 2.81 & 31.9 & 0.76 & 0.94 \\
D2 & 356 & 100 & 32.1 & 93.6 & 2.61 & 3.79 & 30.1 & 0.84 & 1.22 \\
D4 & 446 & 100 & 31.7 & 94.3 & 3.02 & 2.70 & 29.8 & 0.95 & 0.86 \\
D8 & 656 & 99.5 & 29.0 & 91.1 & 5.43 & 3.47 & 26.5 & 1.55 & 1.00 \\
\hline
\end{tabular}


Table 5 Mean $d_{p}$ in different media and volume increase with respect to air

\begin{tabular}{cccccccc}
\hline \multirow{2}{*}{ Catalyst } & DVB & \multicolumn{3}{c}{ Mean $d_{p}{ }^{\mathrm{a}}(\mu \mathrm{m})$} & & \multicolumn{2}{c}{ Volume increase $^{\mathrm{b}}(\%)$} \\
\cline { 3 - 5 } \cline { 7 - 8 } & $\%$ & Air & Water & 1-butanol & & Water & 1-butanol \\
\hline A46 & 25 & 775 & 814 & 825 & & 16 & 21 \\
A35 & 20 & 660 & 724 & 729 & & 32 & 35 \\
A15 & 20 & 650 & 741 & 729 & & 48 & 41 \\
A16 & 12 & 562 & 690 & 630 & & 87 & 40 \\
A36 & 12 & 571 & 729 & 692 & & 108 & 79 \\
A39 & $7-8$ & 540 & 768 & 724 & & 188 & 141 \\
\hline A121 & $<2$ & 441 & 824 & 718 & & 552 & 332 \\
D2 & 2 & 252 & 451 & 383 & & 473 & 250 \\
D4 & 4 & 118 & 163 & 154 & & 165 & 122 \\
D8 & 8 & 167 & 235 & 212 & & 178 & 104 \\
\hline
\end{tabular}

${ }^{\mathrm{a}}$ Determined by laser diffraction

${ }^{\mathrm{b}}$ Calculated as $\left(V_{\text {solvent }}-V_{\text {air }}\right) / V_{\text {air }} \cdot 100$

Figure 6

The behavior among the four gel-type resins was quite similar (Figure 6), although some differences are observed: globally, the system evolves faster at increasing $V_{s p}$ (D8 $<\mathrm{D} 4<$ $\mathrm{D} 2<\mathrm{A} 121)$, i.e., at decreasing DVB percentage. The most active gel-type resin is D2 and the less active D8, showing a relationship between activity and $V_{s p}$ for similar acid capacity (see Figure 8). The initial temperature (contact time equal to zero) was lower and then increased more rapidly for D2 than for the rest of gel-type resins, due to the faster BL production, that also would lead to the disappearance of the temperature maximum in the first minutes of the reaction. The resin A121, with the lowest DVB, behaves similarly to D4 (Fig.6), but its final contact time is longer. Two facts could explain that behavior. On one hand, the large swelling capacity of A121 would induce a large distance between acid centers, and therefore a small value of acid density $\left(H^{+} / V_{s p}=1.52\right)$ compared with that of D2 $\left(H^{+} / V_{s p}=1.80\right)$ with a result of lower catalytic activity. On the other hand, since the 
resin beads of A121 are larger than those of D2 (Table 5), both external and internal mass transfer effects could arise. Results obtained for these gel-type resins are more or less in agreement with those of literature (Table 1) with sizeable differences. For D2, 94\% of LA conversion with excellent selectivity was found after 480 min [21]. The discrepancies can be explained by the effect of water removal on the equilibrium composition, which increases the LA conversion despite the negative effect of higher temperature on the exothermic equilibrium reactions that lead to a decrease the equilibrium conversion. Besides, it takes less time in achieving the highest conversion, only after $153 \mathrm{~min}$ (calculated from Table 5 and Eq.5). The use of fructose as a raw material in experiments of Sharma [16] can explain the discrepancy on selectivity to BL because with fructose there is much more products and byproducts consequence of a reaction network more complex.

Among the assayed macroreticular resins, the evolution rate and the final contact time differ (Figure 7), but no significant differences on LA conversion and on byproducts formation at the end of the runs were found (Table 4), within the experimental error. A36 followed by A39 are the most active, while A46 is the less active. The greater acid capacity of A36 (Table

2, oversulfonated) and its major flexibility and accessibility to acid centers due to its high $V_{s p}$ explain these results. The behavior of A39 can be explained because it has the highest $V_{s p}$ of the macroreticular resins. The lower activity of A46 is due to its lower acid capacity.

\section{Figure 7}

\section{Figure 8}

By comparison of the performance of the pair A15 and A35, which have the same DVB percentage and different acid capacity, it would be expected that water formation (reaction rate) for A35 would be faster. As can be seen in Figure 7 and Table 4 (contact time for $\mathrm{X}_{\mathrm{LA}}=$ 
100), the reaction rate is slightly higher (steeper slope) for A15. In this case, the greater acid capacity of A35 does not compensate for its major rigidity because of oversulfonation, which provokes a more rigid matrix structure and a greater difficulty for reactants to access the acid centers. On the other hand, at the end of the run, the slopes of the profiles for A35 are higher than $\mathrm{A} 15$ showing that $\mathrm{BuOH}$ byproducts would be greater if the experiment was prolonged. In analogy to the A15 and A35, one would expect that A16 was more active than A36, but as shows Figure 7 both temperature and removed water profiles are slightly different, particularly temperature profile. The maximum temperature for A16 occurs much later than for the other resins. This can be ascribed by reviewing Table 3, where it may be observed that the passage area for A16 in the swollen state to gel phase is smaller than for A-36 and the other macroreticular resins of medium crosslinking. Figure 8 shows that there is the same relationship between $V_{\mathrm{sp}}$ and the activity of the resin as for gel-type resins. The activity increases on increasing $V_{\text {sp. }}$.

\subsection{Effect of molar ratio 1-butanol to levulinic acid}

To assess the effect of the $\mathrm{BuOH}$ concentration, a set of experiments was performed at the same conditions than previously, but $R_{B u O H / L A}=1$. Because of the higher initial LA concentration compared to the previous experiments, the boiling point of the reacting mixture is higher. As shown in Figures 9 and 10, the initial temperature was about 115-117 ${ }^{\circ} \mathrm{C}$ for runs catalyzed by gel-type resins and $125-128^{\circ} \mathrm{C}$ for macroreticular ones, respectively. At the end of the experiment, the temperature for gel-type resins was $151-155^{\circ} \mathrm{C}$ and for macroreticular resins was $155-160{ }^{\circ} \mathrm{C}$. A faster reaction rate for gel-type resins and the presence of reaction products with a higher boiling point can explain these temperatures ranges. 
Table 6 shows that the final contact time is now shorter than for experiments with $R_{B u O H / L A}$ $=3$, which means that the reaction proceeds faster, because of the higher concentration of LA. However, the LA conversion is lower, because there is no effect of shifting the equilibrium composition by butanol excess and LA complete conversion is not achieved within the time of the runs. Something similar occurs with the amount of removed water. Now removed water $(28-30 \mathrm{~mL})$ is smaller than the stoichiometric one $(36 \mathrm{~mL})$ for $\mathrm{R}_{\mathrm{BuOH} / \mathrm{LA}}$ $=1$. On the other hand, as expected, $\mathrm{BuOH}$ conversion is higher compared with data of Table 4, and also its selectivity towards $\mathrm{BL}$ as a consequence that fewer byproducts from $\mathrm{BuOH}$ are formed because of its low concentration and shorter reaction time.

Figure 9

Table 6. Conversions, selectivities and contact time for $R_{B u O H / L A}=1$

\begin{tabular}{ccccc}
\hline Catalyst & $\begin{array}{c}\text { Contact } \\
\text { time }\end{array}$ & $\boldsymbol{X}_{\mathbf{L A}}$ & $\boldsymbol{X}_{\text {BuOH }}$ & $\boldsymbol{S}_{\text {BuOH }}^{\text {BL }}$ \\
\hline A46 & 423 & 84.7 & 87 & 97.3 \\
A35 & 393 & 82.1 & 88 & 93.3 \\
A15 & 359 & 82.1 & 87 & 94.3 \\
A16 & 386 & 81.6 & 88 & 92.8 \\
A36 & 355 & 80.2 & 89 & 90.1 \\
A39 & 328 & 83.7 & 89 & 94.0 \\
\hline A121 & 316 & 82.7 & 97 & 95.0 \\
D2 & 232 & 83.4 & 85 & 98.1 \\
D4 & 318 & 83.3 & 86 & 96.8 \\
D8 & 373 & 83.8 & 88 & 95.2 \\
\hline
\end{tabular}

Figure 10 


\section{Conclusions}

The esterification of levulinic acid with 1-butanol is complete with water removal in alcohol stoichiometric excess, catalyzed by acidic ion exchange resins at atmospheric pressure and at the boiling point of the reacting mixture. All tested commercial sulfonic resins (four geltype and six macroreticular) were able to catalyze such reaction, giving similar amounts of byproducts. Gel-type resins have been found to be globally more active than macroreticular ones. Besides, for all resins the lower crosslinking, the better activity. Dowex 50Wx2 would be the most promising acidic resin for this reaction. The selectivity of 1-butanol towards the ester was about $90-95 \%$, and the main byproducts were di-butyl ether and butenes; no humins were detected. A lower levulinic acid conversion was obtained when the initial levulinic acid and 1-butanol amounts were at stoichiometric relation, whereas the reached 1butanol conversion was higher, and byproducts from 1-butanol were formed in a lesser extent.

\section{Nomenclature}

BL butyl levulinate

CNT-PSSA poly(p-styrenesulfonic acid)-grafted carbon nanotubes

$d_{p} \quad$ diameter of the particle, $\mathrm{mm}$

DVB divinyl benzene

$[H]^{+} \quad$ acid capacity, $\mathrm{mmol} / \mathrm{g}$

$[\mathrm{H}]^{+} / V_{\mathrm{sp}} \quad$ density of acid centers in the gel phase of swollen resins, $\mathrm{mmol} / \mathrm{cm}^{3}$

LA levulinic acid 


\begin{tabular}{|c|c|}
\hline$n_{\mathrm{LA}}^{o}$ & initial moles of levulinic acid \\
\hline$n_{\mathrm{BL}}$ & moles of butyl levulinate \\
\hline$n_{\mathrm{BuOH}}^{o}$ & initial moles of 1-butanol \\
\hline$n_{\mathrm{BuOH}}$ & moles of 1-butanol \\
\hline$n_{\text {Butenes }}$ & moles of butenes \\
\hline$n_{\mathrm{DBE}}$ & moles of dibutyl ether \\
\hline$S_{\mathrm{g}}$ & specific surface area, $\mathrm{m}^{2} / \mathrm{g}$ \\
\hline$S_{\mathrm{BuOH}}^{\mathrm{BL}}$ & selectivity of 1-butanol towards butyl levulinate \\
\hline$S_{\text {BuOH }}^{\text {Butenes }}$ & selectivity of 1-butanol towards butenes \\
\hline$S_{B u O H}^{D B E}$ & selectivity of 1-butanol towards dibutyl ether \\
\hline$t$ & time, $\min$ \\
\hline$T$ & temperature, ${ }^{\circ} \mathrm{C}$ \\
\hline$T_{\max }$ & maximum temperature of resins for stability, ${ }^{\circ} \mathrm{C}$ \\
\hline$V_{\mathrm{g}}$ & specific volume of pores, $\mathrm{cm}^{3} / \mathrm{g}$ \\
\hline$V_{\mathrm{sp}}$ & specific volume of gel phase in swollen resins, $\mathrm{cm}^{3} / \mathrm{g}$ \\
\hline$W_{c a t}$ & dried mass of catalyst, $\mathrm{g}$ \\
\hline$X_{\mathrm{BuOH}}$ & percentual conversion of levulinic acid \\
\hline$Y_{\mathrm{BuOH}}^{\mathrm{BL}}$ & yield of 1-butanol towards butyl levulinate \\
\hline
\end{tabular}


$Y_{\mathrm{BuOH}}^{\mathrm{DBE}} \quad$ yield of 1-butanol towards dibutyl ether
$Y_{\mathrm{BuOH}}^{\text {Butenes }} \quad$ yield of 1-butanol towards butenes

\section{Acknowledgments}

Authors thank Dow Water \& Process Solutions for providing ion exchange resins samples and the financial support of MINECO (Spain, grant: CTQ2014-56618-R)

\section{References}

[1] T. Werpy, G. Petersen, Top value-added chemical from biomass. Volumen 1- Results of screening for potential candidates from sugars and synthesis gas. U.S. DNO-NRL http://www.osti.gov./bridge (accessed 20 November 2017).

[2] J.J. Bozell, G.R. Petersen, Green Chem. 12 (2010) 539-554. doi: 10.1039/b922014c.

[3] J. Zhang, S. Wu, H. Li, H. Zhang, ChemCatChem 4 (2012) 1230-1237, doi: $10.1002 /$ cctc. 201200634

[4] H. Kobayashi, A Fukuoka, A., Green Chem. 15 (2013) 1740-1763, doi: $10.1039 / \mathrm{c} 3 \mathrm{gc} 00060 \mathrm{e}$

[5] G. Shrivastav, T. S. Khan, M. Agarwal, M. Ali Haider, ACS Sustain.. Chem. Eng. 5 (2017) 7118-7127, doi: 10.1021/acssuschemeng.7b01316

[6] E. Christensen, A. Williams, S. Paul, S. Burton, R.L. Cormick, Energy Fuel 25 (2011) 5422-5428, doi: 10.1021/ef201229j 
[7] E. Christensen, J. Yanowitz, M. Ratcliff, R.L. McCormick, Energy Fuel 25 (2011) 4723-4733, doi: 10.1021/ef2010089

[8] A. Demolis, N. Essayen, F. Rataboul, ACS Sustain. Chem. Eng. 2 (2014) 1338-1352, doi: $10.1021 / \mathrm{sc} 500082 \mathrm{n}$

[9] H. Jungbluth, K. Gottlieb, R. Wessendorf, Liquids Fuels. Patent WO9421753, 1994.

[10] V.N. Emel'yanenko, E. Altuntepe, C. Held, A.A. Pimerzin, S.P. Verevkin, Thermochim. Acta 659 (2018) 213-221, doi: 10.1016/j.tca.2017.12.006

[11] K.C. Maheria, J Kozinski, A. Dalai., Catal. Lett. 143 (2013) 1220-1225, doi: $10.1007 / \mathrm{s} 10562-013-1041-3$

[12] K.Y. Nandiwale, V.V., Bokade, Chem. Eng. Technol. 38 (2015) 246-252, doi: 10.1002/ceat.201400326

[13] S. Dharne, V.V. Bokade, J. Nat. Gas Chem. 20 (2011) 18-24, doi: 10.1016/S10039953(10)60147-8

[14] K. Manikandan, K.K. Cheralathan, K.K., Appl. Catal. A: Gen. 547 (2017) 237-247, doi: 10.1016/j.apcata.2017.09.007

[15] M.A. Tejero, E., Ramirez, C. Fité, J. Tejero, F. Cunill, Appl. Catal. A 517 (2016) 5666, doi: 10.1016/j.apcata.2016.02.032

[16] R.A. Sharma, Bachelor Degree Project. University of Barcelona (2016).

[17] V. Trombettoni, L. Bianchi, A. Zupanic, A. Porciello, M. Cuomo, O. Piernatti, A. Marrocchi, L. Vaccaro, Catalysts 7 (2017) 235-24., doi: 10.3390/catal7080235

[18] M. Popova, A. Szegedi, H. Lazarova, A. Ristic, Y. Kalvachev, G. Atanasova, N. Wilde, N.N. Tusar, R. Glaser, Micro. Meso. Mat. 235 (2016) 50-58, doi: 10.1016/j.micromeso.2016.07.047 
[19] F.G. Cirujano, A. Corma, F.X. Llabrés, Chem. Eng. Sci. 124 (2015) 52-60, doi: 10.1016/j.ces.2014.09.047

[20] A.N. Chermahini, M. Nazeri, Fuel Process. Technol. 167 (2017) 442-450, doi: 10.1016/j.fuproc.2017.07.034

[21] R. An, G. Xu, C. Chang, J. Bai, S. Fang, J. Energy Chem. 26 (2017) 556-563, doi: 10.1016/j.jechem.2016.11.015

[22] S. Zhou, D. Jiang, X. Liu, Y. Chen, D. Yin, RSC Adv. 8 (2018) 3657-3662, doi: $10.1039 / \mathrm{c} 7 \mathrm{ra} 12994 \mathrm{~g}$

[23] Y. Yang, G. Li, L. Zhang, S. Zhang, Catalysis 8 (2018) 14, doi: 10.3390/catal8010014

[24] G.D. Yadav, I.V. Borkar, Ind. Eng. Chem. Res. 47 (2008) 3358-3363, doi: 10.1021/ie800193f

[25] R.R. Chada, K.S. Koppadi, S.S. Enumula, M. Kondeboina, Catal. Lett. 148 (2018) 1731-1738, doi: 10.1007/s10562-018-2371-y

[26] S.R. Rao, K.P. Kumari, D.D. Lakshimi, N. Lingaiah, Catal. Today 309 (2018) 269275, doi: 10.1016/j.cattod.2017.05.040

[27] M.G. Al-Shaal, W. Ciptonugroho, F.J. Holzhäuser, J.B. Mensah, P.J.C. Hausoul, R. Palkovits, Catal. Sci. Technol. 5 (2015) 5168-5173, doi: 10.1039/c5cy00446b

[28] W. Ciptonugroho, G. Al-Shaal, J.B. Mensah, R. Palkovits, J. Catal. 340 (2016) 17-29, doi: 10.1016/j.jcat.2016.05.001

[29] A. Demolis, M. Eternot, N. Essayem, F. Rataboul, New J. Chem. 40 (2016) 37473754, doi: 10.1039/c5nj02493e

[30] L. Deng, Ch. Chang, R. An, X. Qi, G. Xu, Cellulose 24 (2017) 5403-5415, doi: $10.1007 / \mathrm{s} 10570-017-1530-4$ 
[31] X. Hu, C. Li, Green Chem. 13 (2011) 1676-1679, doi: 10.1039/c1gc15272f

[32] I. Van Zandvoort, Y. Wang, C.B. Rasrendra, E.R.H. van Eck, P.C.A., Bruijnincx, H.J. Heeres, M.W. Bert, ChemSusChem. 6 (2013) 1745-1758, doi: $10.1002 /$ cssc. 201300332

[33] P. Tang, J. Yu, Ind. Eng. Chem. Res. 53 (2014) 11629-11637, doi: 10.1021/ie501044c

[34] R. Liu, J. Chen, X. Huang, M. Chen, L. Ma, X. Li, X., Green Chem. 15 (2013) 28952903, doi: $10.1039 / \mathrm{c} 3 \mathrm{gc} 41139 \mathrm{~g}$

[35] B. Corain, M. Zecca, K. Jerabek, J. Mol. Catal. A: Chemical 177 (2001) 3-20, doi: $10.1016 / \mathrm{S} 1381-1169(01) 00305-3$

[36] K. Jerabek, Anal. Chem. 57 (1985) 1598-1602, doi: 10.1021/ac00285a022

[37] A.G. Ogston, Trans. Faraday Soc. 54 (1958) 1754-1757, doi: 10.1039/TF9585401754

[38] M.A. Pérez, R. Bringué, M. Iborra, J. Tejero, F. Cunill, F., Appl. Catal. A: Gen. 482 (2014) 38-48, doi: 10.1016/j.apcata.2014.05.017 


\section{FIGURE CAPTIONS}

Figure 1. Reaction scheme in the esterification of levulinic acid by 1-butanol.

Figure 2. Levulinic acid esterification with 1-BuOH to p- and n-butyl levulinate [28].

Figure 3. Morphological changes during swelling of a gel-type and macroreticular catalyst particle in water.

Figure 4. Experimental device

Figure 5. Temperature and removed water profiles versus contact time, (atmospheric pressure, $2.85 \mathrm{~g} \mathrm{A15,} R_{\mathrm{BuOH} / \mathrm{LA}}=3$ ).

Figure 6. Evolution of the reacting medium temperature and removed for gel-type resins (atmospheric pressure, $R_{\mathrm{BuOH} / \mathrm{LA}}=3$ ).

Figure 7. Temperature and removed water evolution of the reacting system versus contact time for macroreticular resins (atmospheric pressure, $R_{\mathrm{BuOH} / \mathrm{LA}}=3$ ).

Figure 8. Contact time versus volume of gel phase.

Figure 9. Temperature and removed water evolution of the reacting system versus contact time for gel-type resins (atmospheric pressure, $R_{B u O H / L A}=1$ ).

Figure 10. Temperature and removed water evolution of the reacting system versus contact time for macroreticular resins (atmospheric pressure, $R_{B и O H / L A}=1$ ). 


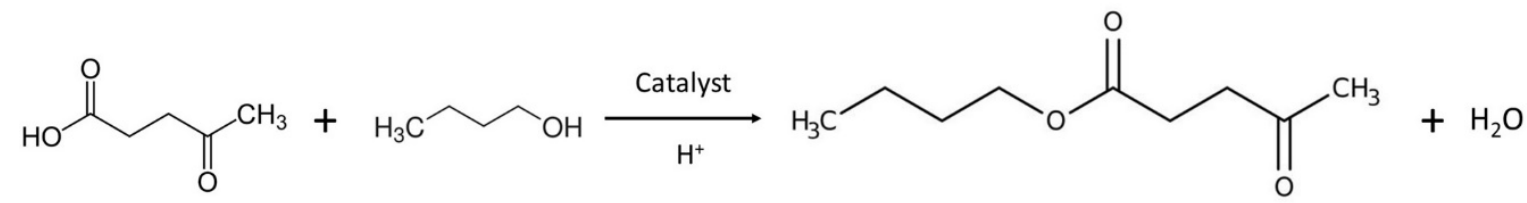

LEVULINIC ACID N-BUTANOL N-BUTYL LEVULINATE

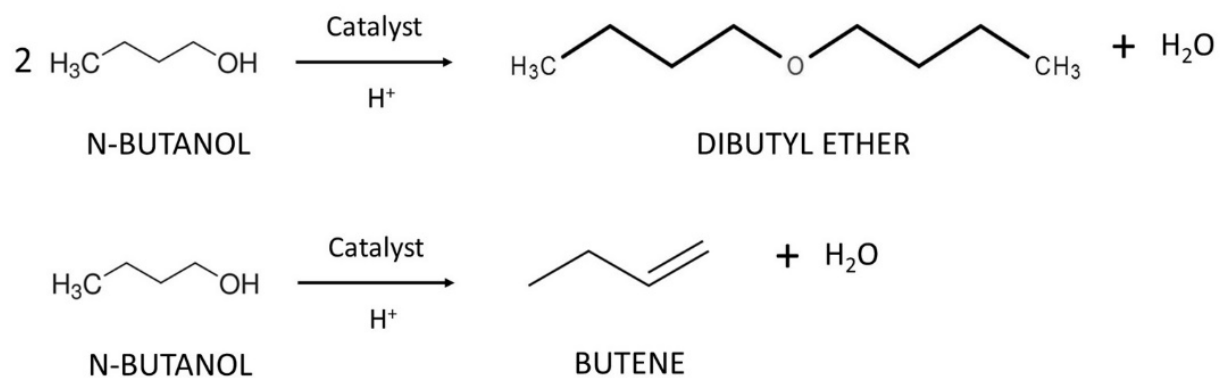

FIGURE 1<smiles>CC(=O)CCC(=O)O</smiles>

Levulinic acid (LA)<smiles>OCCCC1C=CCC1</smiles>

1-butanol (BuOH)

\section{$\underset{-\mathrm{H}_{2} \mathrm{O}}{\rightleftharpoons}$}

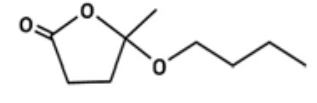

pseudo-butyl levulinate ( $p-B \mathrm{~L})$
$\left[\mathrm{H}^{+}\right]$<smiles>CCCCOC(=O)CCC(C)=O</smiles>
normal-butyl levulinate ( $n-\mathrm{BL})$

FIGURE 2 


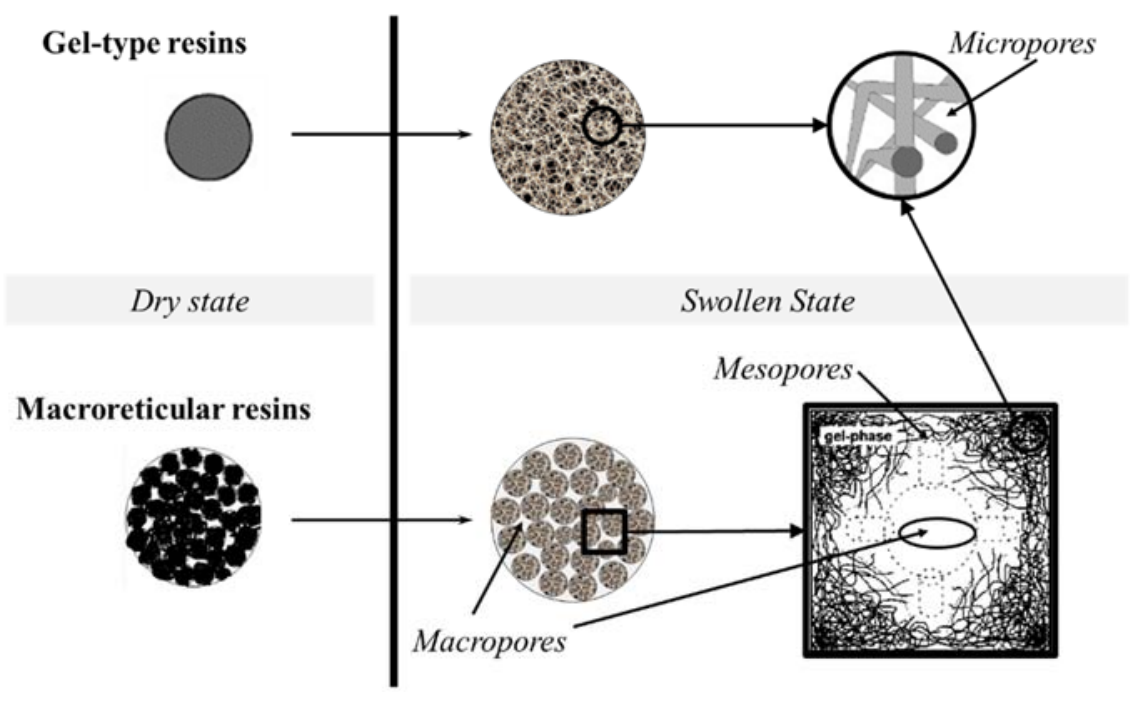

FIGURE 3 


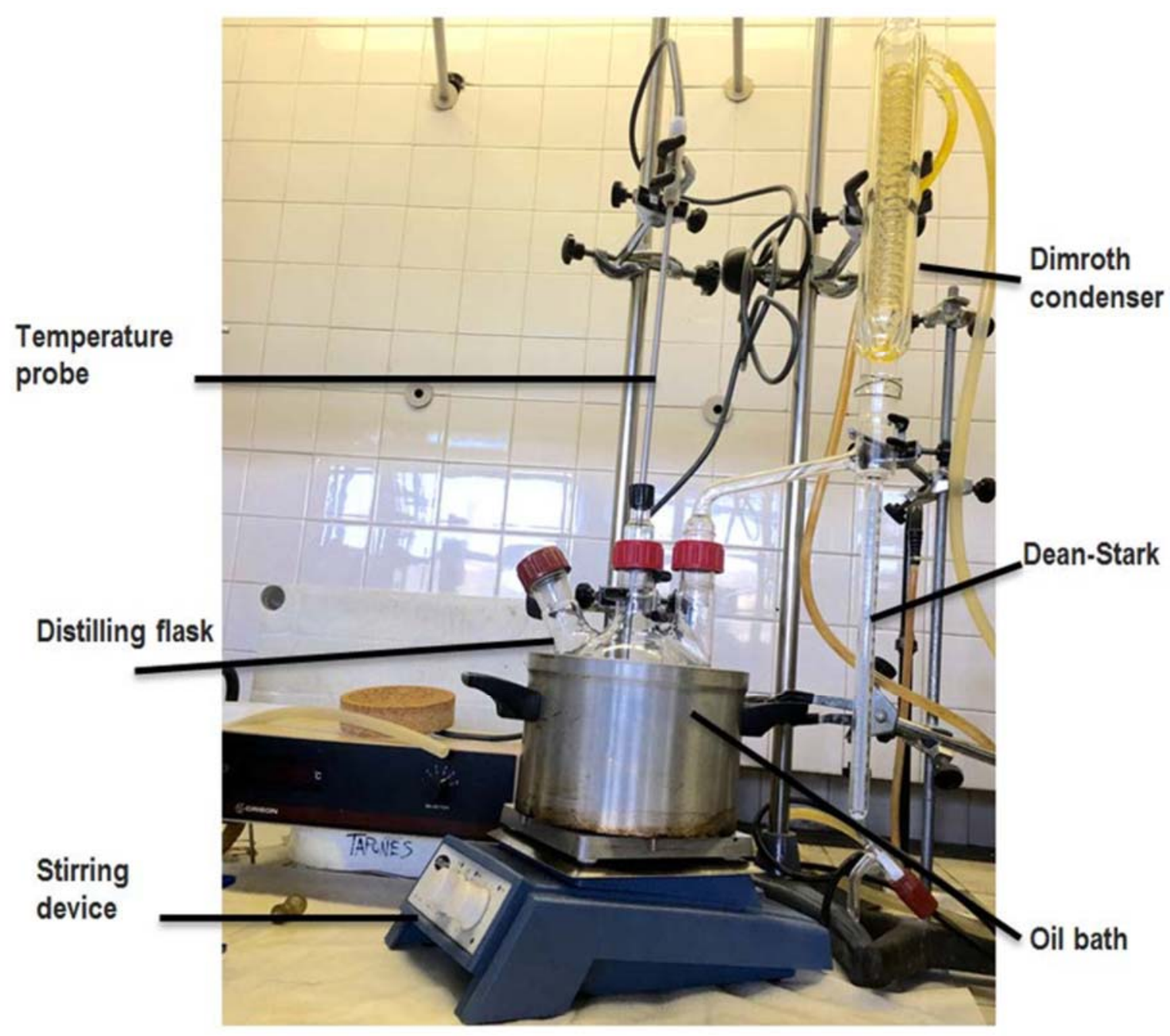

FIGURE 4 


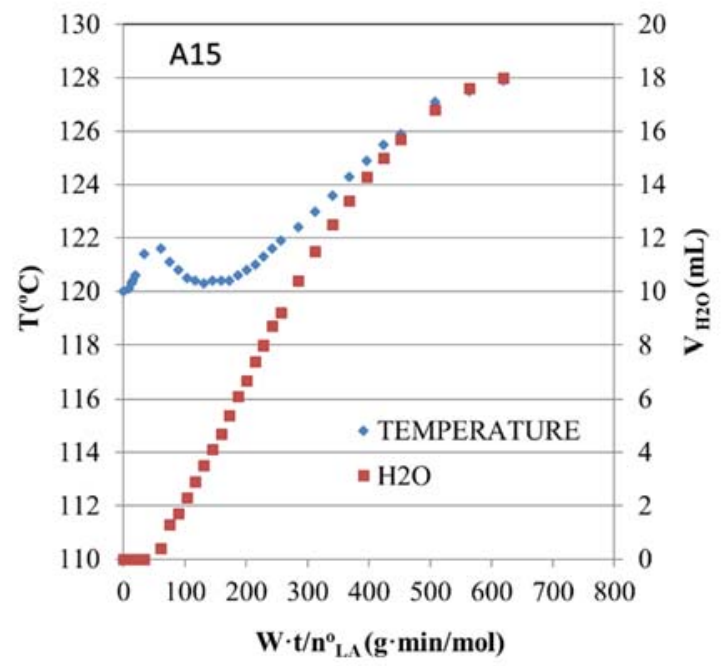

FIGURE 5 

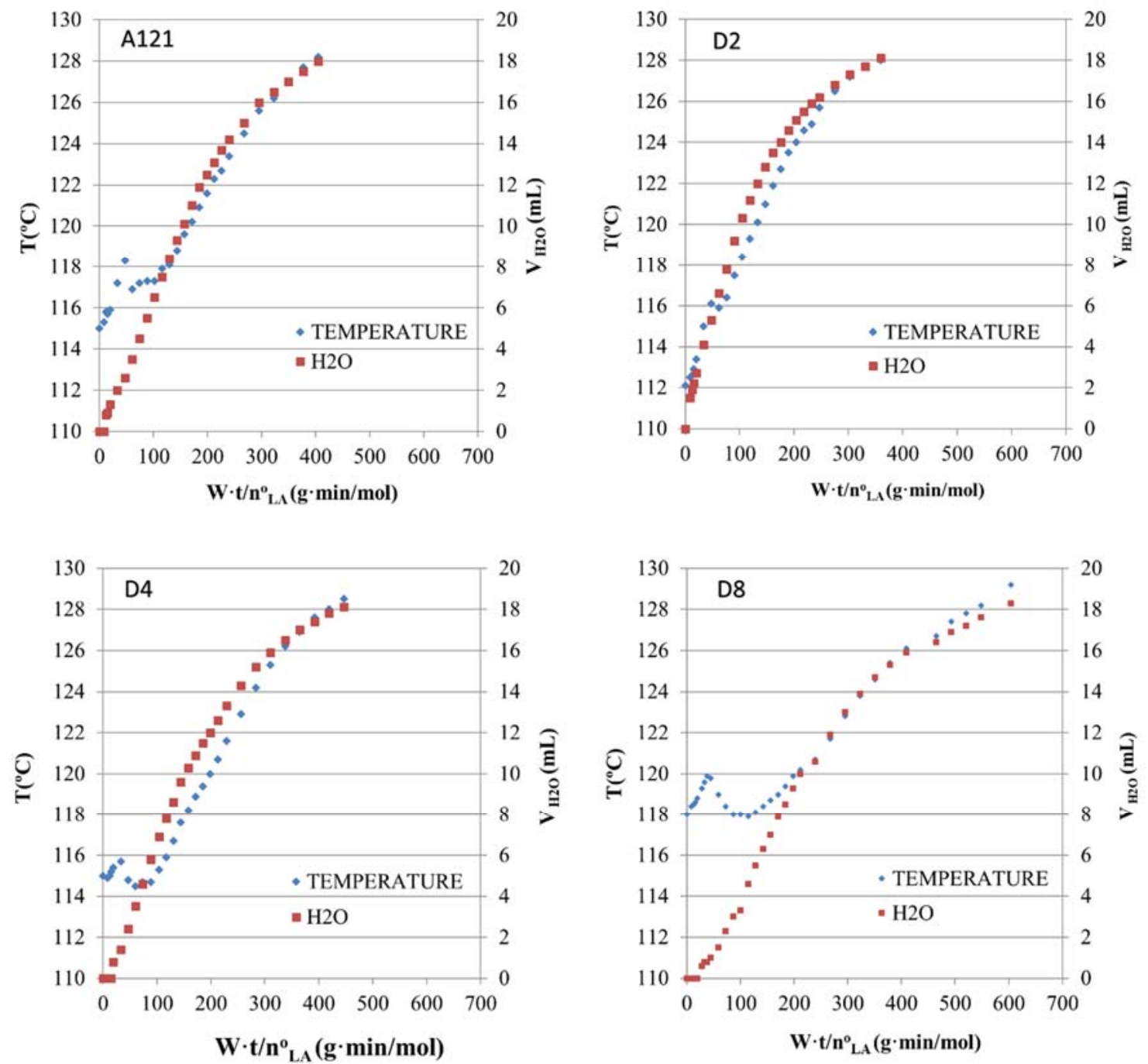

FIGURE 6 


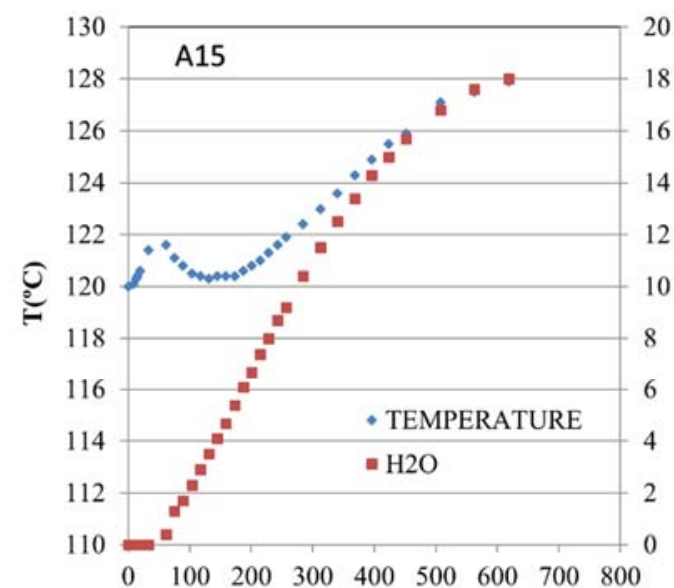

$\mathrm{W} \cdot \mathrm{t} / \mathrm{n}^{\mathrm{o}}{ }_{\mathrm{IA}}(\mathrm{g} \cdot \mathrm{min} / \mathrm{mol})$
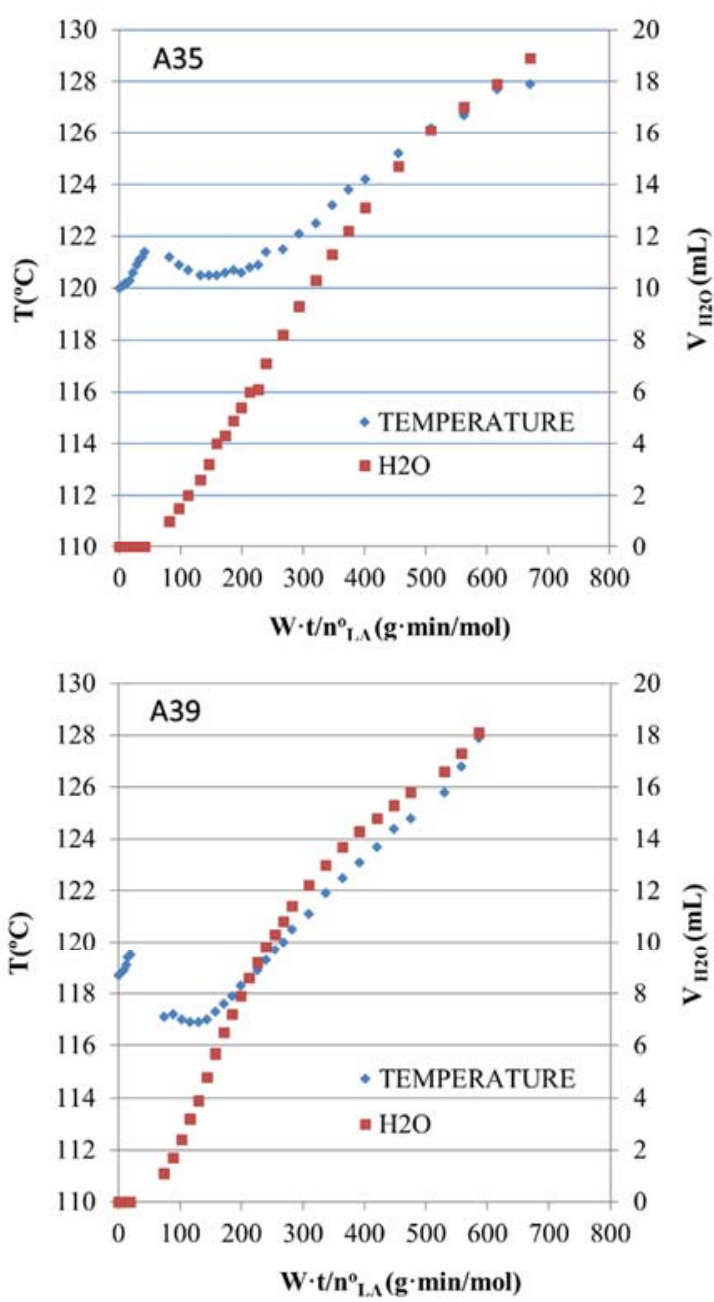

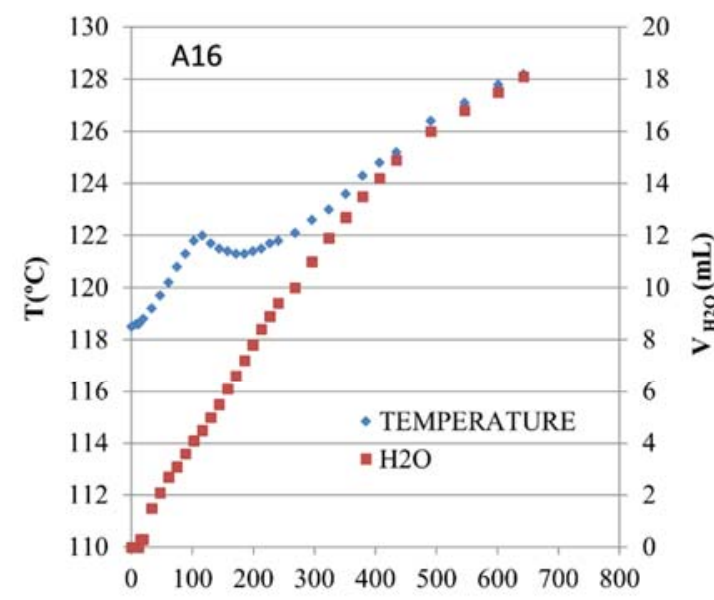

$\mathrm{W} \cdot \mathrm{t} / \mathbf{n}^{\circ}{ }_{\mathrm{LA}}(\mathrm{g} \cdot \mathrm{min} / \mathrm{mol})$

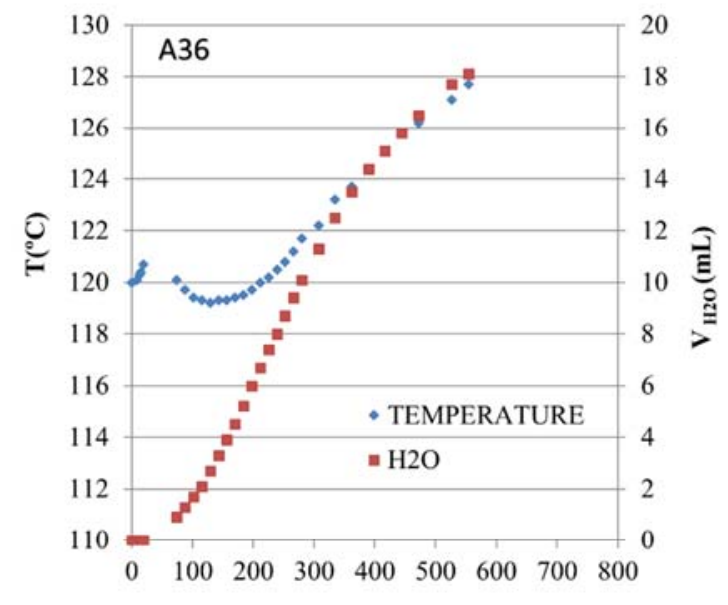

$\mathbf{W} \cdot \mathbf{t} / \mathbf{n}^{\circ}{ }_{\mathrm{LA}}(\mathrm{g} \cdot \mathrm{min} / \mathrm{mol})$

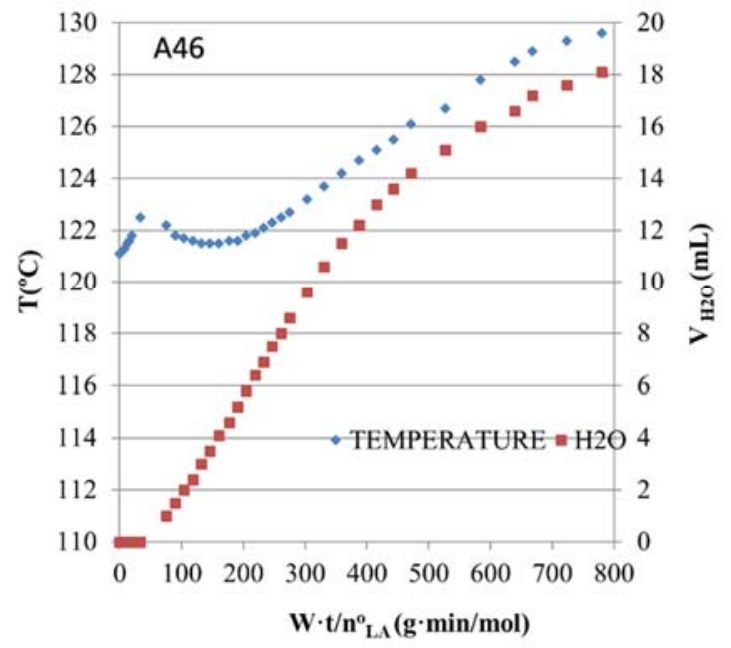

FIGURE 7 


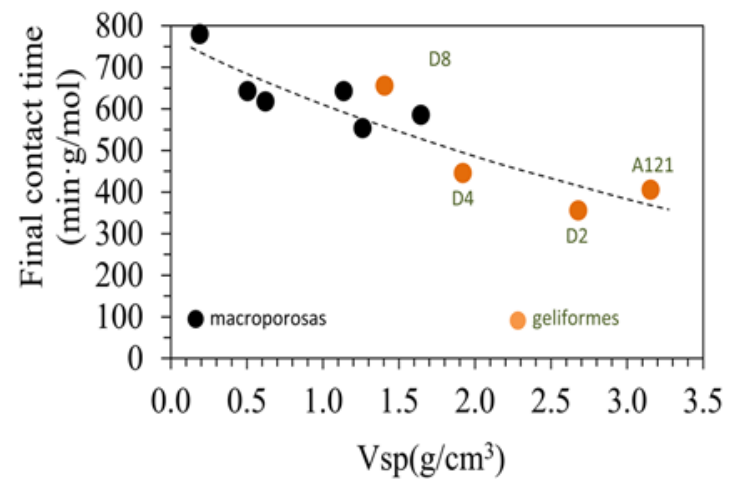

FIGURE 8
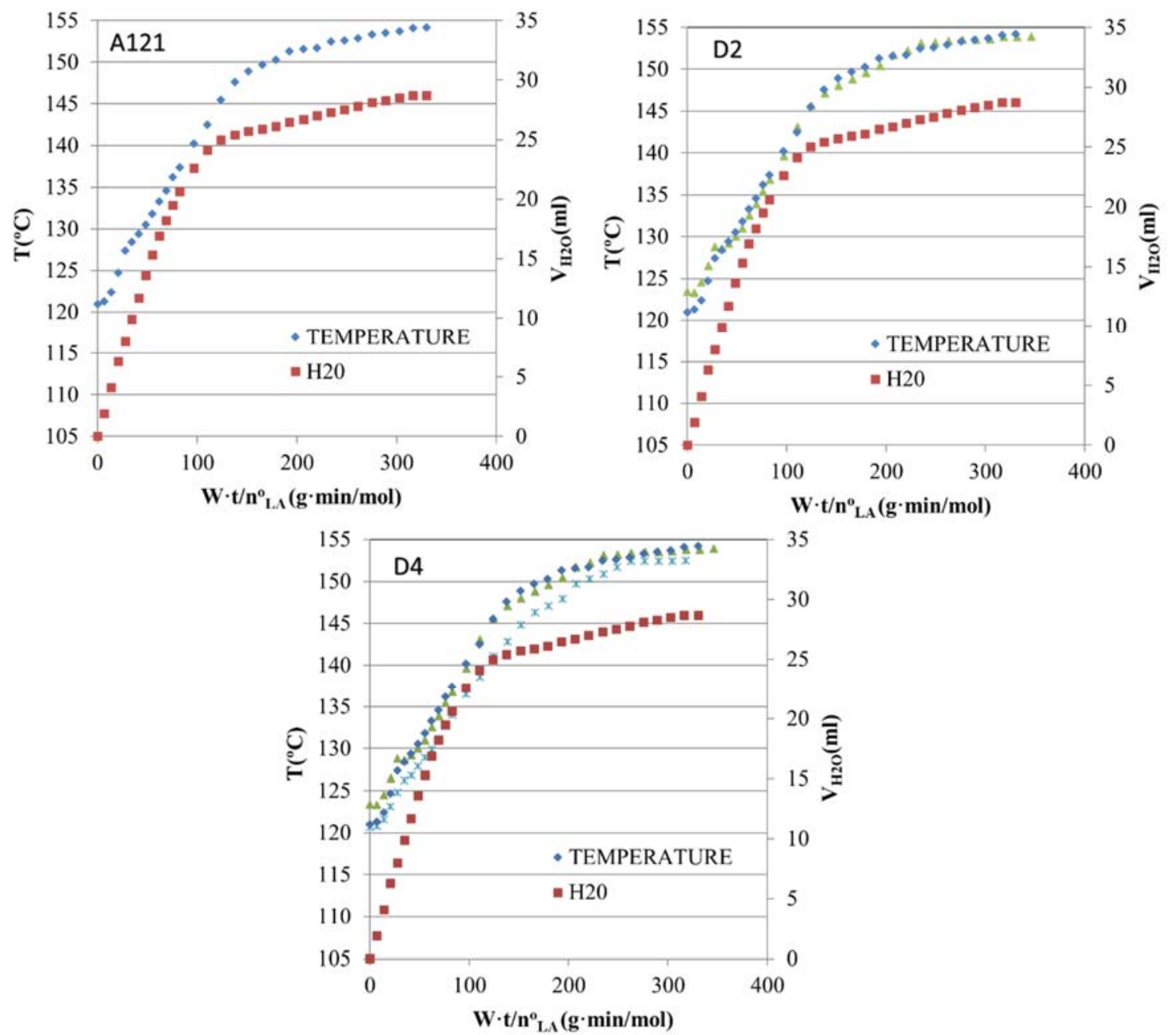

FIGURE 9 

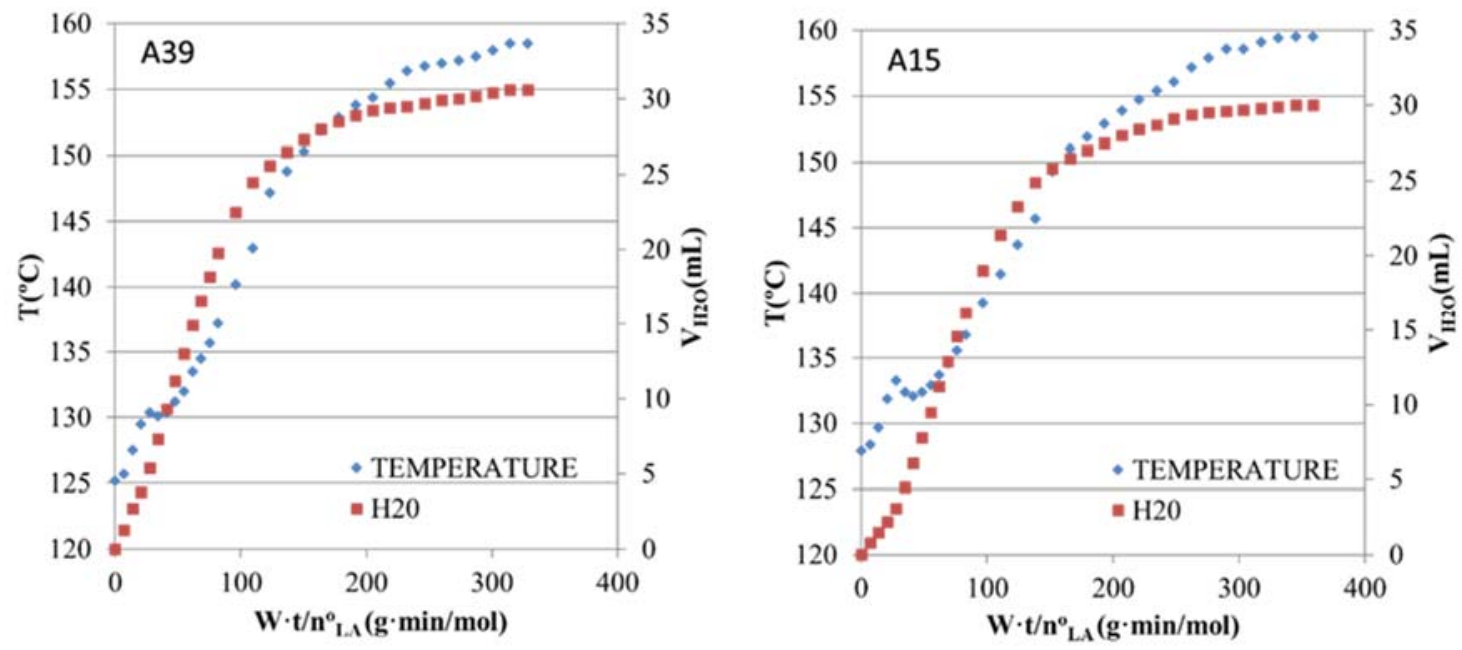

FIGURE 10 